(c) American Dairy Science Association, 2003.

\title{
Genetic Analysis of Somatic Cell Score in Norwegian Cattle Using Random Regression Test-Day Models
}

\author{
J. Ødegård, ${ }^{\star}$ J. Jensen, $†$ G. Klemetsdal,, ${ }^{*}$ P. Madsen,† and B. Heringstad* \\ *Department of Animal Science, Agricultural University of Norway, \\ P.O. Box 5025, N-1432 Ås, Norway \\ †Department of Animal Breeding and Genetics, \\ Danish Institute of Agricultural Sciences, \\ Research Centre Foulum, \\ DK-8830 Tjele, Denmark
}

\section{ABSTRACT}

The dataset used in this analysis contained a total of 341,736 test-day observations of somatic cell scores from 77,110 primiparous daughters of 1965 Norwegian Cattle sires. Initial analyses, using simple random regression models without genetic effects, indicated that use of homogeneous residual variance was appropriate. Further analyses were carried out by use of a repeatability model and 12 random regression sire models. Legendre polynomials of varying order were used to model both permanent environmental and sire effects, as did the Wilmink function, the Lidauer-Mäntysaari function, and the Ali-Schaeffer function. For all these models, heritability estimates were lowest at the beginning (0.05 to 0.07) and higher at the end ( 0.09 to 0.12 ) of lactation. Genetic correlations between somatic cell scores early and late in lactation were moderate to high ( 0.38 to 0.71 ), whereas genetic correlations for adjacent DIM were near unity. Models were compared based on likelihood ratio tests, Bayesian information criterion, Akaike information criterion, residual variance, and predictive ability. Based on prediction of randomly excluded observations, models with 4 coefficients for permanent environmental effect were preferred over simpler models. More highly parameterized models did not substantially increase predictive ability. Evaluation of the different model selection criteria indicated that a reduced order of fit for sire effects was desireable. Models with zeroth- or firstorder of fit for sire effects and higher order of fit for permanent environmental effects probably underestimated sire variance. The chosen model had Legendre polynomials with 3 coefficients for sire, and 4 coefficients for permanent environmental effects. For this model, trajectories of sire variance and heritability

Corresponding author: Jørgen Ødegård; e-mail: jorgen.odegard@ ihf.nlh.no.

Received April 13, 2003.

Accepted August 4, 2003. were similar assuming either homogeneous or heterogeneous residual variance structure.

(Key words: dairy cattle, model comparison, random regression model, somatic cell score)

Abbreviation key: $2 \ln R \mathbf{L}=2 \ln$ restricted likelihood, $\mathbf{A I C}=$ Akaike information criterion, $\mathbf{A S}=$ Ali-Schaeffer curve, BIC = Bayesian information criterion, $\mathbf{C M}=$ clinical mastitis, $\mathbf{L}=$ Legendre polynomial, $\mathbf{L M}=\mathrm{Li}$ dauer-Mäntysaari curve, LSCS = lactation average somatic cell score, MSEP = mean squared error of predictions, $\mathbf{N R F}=$ Norwegian Cattle, $\mathbf{P E}=$ permanent environmental, $\mathbf{R E P}$ = repeatability model, $\mathbf{R R}$ = random regression, $\mathbf{R R M}=$ random regression model, $\mathbf{W}=$ Wilmink curve.

\section{INTRODUCTION}

Mastitis is the most costly disease affecting dairy cows. Reducing the incidence of mastitis through genetic selection is therefore of great importance both for economical and animal welfare reasons. Mastitis has an unfavorable genetic correlation with milk production (Madsen et al., 1987; Mrode and Swanson, 1996; Heringstad et al., 2000), and selection for increased milk production is therefore expected to increase the incidence of the disease. However, if selection against mastitis is included in a total merit index, the genetic level of mastitis may be kept constant or even improved (Heringstad et al., 2003). Selection can be either direct using clinical mastitis (CM) records; indirect via information on traits that are genetically correlated to mastitis, such as SCC; or a combination of both. Denmark, Finland, Norway, and Sweden are the only countries having national recording systems for CM (Heringstad et al., 2000), whereas SCC is routinely recorded in many countries (International Bull Evaluation Service, 1996). In the latter, genetic improvement of udder health relies mainly on selection for reduced SCC. Typically, the information used for genetic evaluation consists of lactation average SCS 
(LSCS), which has higher heritability than CM (Mrode and Swanson, 1996). Ødegård et al. (2003) reported that the sire's PTA for LSCS in first-crop daughters had a moderate, but highly significant, relationship with incidence of CM in second-crop daughters. However, it was shown that direct selection for reduced incidence of CM would be 23 to $43 \%$ more efficient in terms of reducing incidence of clinical mastitis among second-crop daughters, than indirect selection using LSCS.

A genetic analysis based on LSCS does not utilize all information in the data, as it does not allow simultaneous estimation of stage of lactation effects. In addition, cows may have different numbers of records per lactation, which is not accounted for in most models for genetic evaluation based on LSCS. However, a testday model has the potential of inducing more precise adjustment for temporary environmental effects (Jensen, 2001) and for stage of lactation. Test-day models are therefore expected to result in more accurate genetic evaluations than models based on LSCS.

Test-day SCS can be modeled as repeated measurements of the same trait, but this may be suboptimal because genetic correlations between SCS at different stages of lactation are less than unity (Reents et al., 1994; Mrode et al., 1998; Haile Mariam et al., 2001). Alternatively, SCS at all different DIM could be regarded as separate traits. This assumption may lead to a nonparsimonious model and require estimation of (co)variance components for all DIM, which is computationally difficult. Random regression models (RRM) are a compromise between a simple repeatability (REP) model and a model regarding all SCS at different DIM as separate traits. Such models may be well suited for test-day analysis of longitudinal traits because the random regression ( $\mathbf{R R}$ ) coefficients induce a covariance structure along a given trajectory (Van der Werf et al., 1998). A suitable specification of a RRM may lead to a parsimonious account of the (co)variance structure across DIM.

The objectives of this study were to evaluate different test-day models, such as a REP model and RRM using orthogonal polynomials and standard linear lactation functions for modelling sire and permanent environmental (PE) effects, and to estimate genetic parameters for test-day SCS in Norwegian Cattle (NRF).

\section{MATERIALS AND METHODS}

\section{Data}

In Norway, SCC is recorded in most herds on a bimonthly basis. Records for cows included in a pedigree file for the NRF population, described by Heringstad et al. (1999), were used in the analyses. Data were
Table 1. Summary statistics of data from three counties in central eastern Norway (Akershus, Østfold and Vestfold) used for model evaluation.

\begin{tabular}{lc}
\hline Records & 341,736 \\
Cows & 77,110 \\
Mean records per cow & 4.43 \\
Sires & 1965 \\
Mean daughters per sire & 39.2 \\
Herd-year classes & 15,894 \\
Mean records per herd-year class & 21.5 \\
Herd test-day classes & 88,368 \\
Mean SCS & (SD) \\
Calving year & $4.18(1.17)$ \\
\hline
\end{tabular}

${ }^{1} \mathrm{SCS}=\ln \left((\mathrm{SCC} / \mathrm{ml}) \times 10^{-3}\right)$.

restricted to primiparous cows, calving between September 1, 1978, and December 31, 1995, that met the following requirements: 1 ) age at first calving between 450 and $1200 \mathrm{~d}, 2)$ lactation had to start with a normal calving (lactations starting with abortion or calving in another herd were deleted), and 3) test days from 6 to 305 DIM. Only daughters of sires with first progeny test from 1978 to 1995 were used. SCC records outside the range 5000 to $6,400,000 \mathrm{cell} / \mathrm{s} / \mathrm{ml}$ were discarded $(0.16 \%)$. As a lognormal distribution fits well to SCC (Schukken et al., 1992), the observations were transformed to SCS $\left[\mathrm{SCS}=\ln \left((\mathrm{SCC} / \mathrm{ml}) \times 10^{-3}\right)\right]$ to achieve an approximate normal distribution of the test-day records.

To reduce computational burden, data were restricted to herds from three counties (Akershus, Østfold, and Vestfold) in the central eastern part of Norway, resulting in a dataset of 341,736 test-day observations from 77,110 cows. Descriptive statistics of the dataset are presented in Table 1 . The pedigrees of the 1965 sires in the dataset were traced back as far as possible through sires and maternal grandsires, resulting in a pedigree with 2275 males.

\section{Models}

The data were analyzed using a standard REP and RRM using different RR functions. All models had the following general characteristics:

$$
\begin{aligned}
Y_{i j k l m p q}=A_{i}+ & M_{j}+H Y_{k}+D I M_{l}+h t d_{m}+\sum_{n=0}^{r} r_{p n} Z_{\mathrm{ln}} \\
& +\sum_{n=0}^{t} r_{q n} Z_{\mathrm{ln}}+e_{i j k l m p q}
\end{aligned}
$$

where:

$\mathrm{Y}_{i j k l m p q}=$ observation of SCS for daughter $p$ of sire $q$, with age at calving $i$, calving month $j$, DIM $l$, herd-year class $k$, and herd test-day $m$; 
$\mathrm{A}_{i}=$ fixed effect of age $i$ at first calving, in 15 classes; where $<20 \mathrm{mo}$ is the first class, $>32$ mo the last class, and the other classes are in single months;

$\mathrm{M}_{j}=$ fixed effect of month $j$ of first calving in 12 classes;

$\mathrm{HY}_{k}=$ fixed effect of herd-year class $k$;

$\operatorname{DIM}_{l}=$ fixed effect of DIM $l$ in 300 classes where 6 $\mathrm{d}$ is the first class and, $305 \mathrm{~d}$ the last class; $\mathrm{htd}_{m}=$ random effect of herd test-day $m$;

$\mathrm{Z}_{l n}=$ polynomial $n$ for DIM $l$, where $\mathrm{n}=\{0, \ldots, \mathrm{r}\}$ for permanent environmental effects and $n$ $=\{0, \ldots, t\}$ for sire effects;

$\mathrm{r}_{p n}=$ random regression coefficient on $\mathrm{Z}_{l n}$, for the permanent environmental effect $p$;

$\mathrm{r}_{q n}=$ random regression coefficient on $\mathrm{Z}_{l n}$, for the transmitting ability of sire $q$; and

$\mathrm{e}_{i j k l m p q}=$ random residual.

The following polynomials were used to model PE and sire effects:

- Legendre polynomials up to fourth order $\left(\operatorname{Leg}_{1}, \operatorname{Leg}_{2}\right.$, $\operatorname{Leg}_{3}, \operatorname{Leg}_{4}$ ).

- Modified Wilmink function (Wilmink, 1987);

$y=a_{0}+a_{1} D I M^{*}+a_{3} E D I M$

where: $\mathrm{DIM}^{*}=\left(\mathrm{DIM}-\mathrm{DIM}_{\min }\right) /\left(\mathrm{DIM}_{\max }-\mathrm{DIM}_{\min }\right)$ $=(\mathrm{DIM}-6) / 299 ;$ and $\mathrm{EDIM}=\mathrm{e}^{-0.05 \mathrm{DIM}}$

- Modified Ali and Schaeffer (AS) function (Ali and Schaeffer, 1987);

$y=a_{0}+a_{1}(D I M / 305)+a_{2}(D I M / 305)^{2}+$

$a_{3} \ln (305 / D I M)$

The original five-parameter curve of Ali and Schaeffer (1987) was not used due to convergence problems.

An overview of the models is given in Table 2. All models included an intercept $\left(\mathrm{Z}_{l 0}=1\right)$ for both $\mathrm{PE}$ and sire effects (if included). For the sire models, the PE variance will contain three quarters of the additive genetic variance.

The analysis was carried out in three steps. In the first step, 2 models were analyzed (L04 and L05), using the ASREML-package (Gilmour, et al., 1999), assuming both homogeneous and heterogeneous residual variances. For these models, the PE effects were used to model permanent effect of cow and sire effects were removed from the model. For the heteroscedastic models, residual variances were estimated for 10 lactation periods of equal length $(30 \mathrm{~d})$. In the second step, for the remaining 13 models in Table 2 , both $\mathrm{PE}$ and sire effects were fitted and evaluated, using the DMUpackage (Madsen and Jensen, 2000) assuming homogeneous residual variance. The DMU-package did not allow for heterogeneous residual variances, but allowed running the most complex models with our data. In the third step, results were also obtained for the preferred model from the second step, assuming heterogeneous residual variance, using the ASREMLpackage.

The REP model is a special case of the general RRM where only an intercept is included in the PE and sire effects $\left(\mathrm{Z}_{l 0}=1\right.$, and $\mathrm{Z}_{l n}=0$ for $\left.n>0\right)$. The LM44 model (Lidauer and Mäntysaari, 1999) is a combination of Legendre polynomials and the curve described by Wilmink (1987). For this model, higher order of fit was not used due to convergence problems. For 7 of the RRM, the same functions were used to model both sire and PE effects, whereas 5 RRM used Legendre polynomials of lower order of fit for the sire effect than for the PE effect.

Sire variance $\left(\sigma_{s_{\mathrm{i}}}^{2}\right), \mathrm{PE}$ variance $\left(\sigma_{c_{\mathrm{i}}}^{2}\right)$, and heritability $\left(h_{l}^{2}\right)$ at DIM $l$ were calculated as:

$$
\begin{gathered}
\sigma_{s_{1}}^{2}=\mathbf{Z}_{\mathbf{l}}^{\prime} \mathbf{G} \mathbf{Z}_{\mathbf{l}} \\
\sigma_{s_{1}}^{2}=\mathbf{Z}_{\mathbf{l}}^{\prime} \mathbf{P} \mathbf{Z}_{\mathbf{l}} \\
h_{l}^{2}=\frac{4 \sigma_{s_{1}}^{2}}{\sigma_{s_{1}}^{2}+\sigma_{c_{1}}^{2}+\sigma_{e}^{2}}
\end{gathered}
$$

where:

$$
\begin{aligned}
\mathbf{Z}_{\mathbf{1}} & =\text { vector of polynomials in the model for DIM } l ; \\
\mathbf{G} & =\text { (co)variance matrix for sire RR coefficients; } \\
\mathbf{P} & =\text { (co)variance matrix for PE RR coefficients; and } \\
\sigma_{e}^{2} & =\text { residual variance. }
\end{aligned}
$$

If the PE curve has a lower order of fit than the genetic curve, the larger flexibility of the genetic curve may capture changes in the PE curve (Pool and Meuwissen, 1999; Kettunen et al., 2000), overestimating heritability. To examine the opposite, to what degree an increased order of fit for the PE effect relative to the sire effect could affect (co)variance components, models with fourth-order Legendre polynomials for PE effect and reduced order of fit for sire effect were tested (L15, L25, L35, and L45).

\section{Model Comparison}

Models were compared in terms of the residual variance, $2 \mathrm{ln}$ restricted likelihood (2lnRL), and mean square error of prediction (MSEP) for excluded obser- 
Table 2. Models fitted. For each model, polynomials used for random regression of permanent environmental $(\mathrm{PE})$ and sire effects are marked with $\boldsymbol{} \mathcal{}$.

\begin{tabular}{|c|c|c|c|c|c|c|c|c|c|c|c|}
\hline Model & & Intercept & $\operatorname{Leg}_{1}$ & $\operatorname{Leg}_{2}$ & $\operatorname{Leg}_{3}$ & $\operatorname{Leg}_{4}$ & $\mathrm{DIM}^{*}$ & EDIM & DIM/305 & $(\mathrm{DIM} / 305)^{2}$ & $\ln (305 / \mathrm{DIM})$ \\
\hline L04 & $\begin{array}{l}\mathrm{PE} \\
\text { sire }\end{array}$ & $\checkmark$ & $\checkmark$ & $\checkmark$ & $\checkmark$ & & & & & & \\
\hline L05 & $\begin{array}{l}\mathrm{PE} \\
\text { sire }\end{array}$ & $\checkmark$ & $\checkmark$ & $\checkmark$ & $\checkmark$ & $\checkmark$ & & & & & \\
\hline REP & $\begin{array}{l}\mathrm{PE} \\
\text { sire }\end{array}$ & $\begin{array}{l}\checkmark \\
\checkmark\end{array}$ & & & & & & & & & \\
\hline L22 & $\begin{array}{l}\mathrm{PE} \\
\text { sire }\end{array}$ & $\begin{array}{l}\checkmark \\
\checkmark\end{array}$ & $\begin{array}{l}\checkmark \\
\checkmark\end{array}$ & & & & & & & & \\
\hline L33 & $\begin{array}{l}\mathrm{PE} \\
\text { sire }\end{array}$ & $\begin{array}{l}\checkmark \\
\checkmark\end{array}$ & $\checkmark$ & $\begin{array}{l}\checkmark \\
\checkmark\end{array}$ & & & & & & & \\
\hline W33 & $\begin{array}{l}\mathrm{PE} \\
\text { sire }\end{array}$ & $\begin{array}{l}\checkmark \\
\checkmark\end{array}$ & & & & & $\begin{array}{l}\checkmark \\
\checkmark\end{array}$ & $\checkmark$ & & & \\
\hline L44 & $\begin{array}{l}\mathrm{PE} \\
\text { sire }\end{array}$ & $\checkmark$ & $\begin{array}{l}\checkmark \\
\checkmark\end{array}$ & $\begin{array}{l}\checkmark \\
\checkmark\end{array}$ & $\begin{array}{l}\checkmark \\
\checkmark\end{array}$ & & & & & & \\
\hline LM44 & $\begin{array}{l}\mathrm{PE} \\
\text { sire }\end{array}$ & $\begin{array}{l}\checkmark \\
\checkmark\end{array}$ & $\checkmark$ & $\checkmark$ & & & & $\checkmark$ & & & \\
\hline $\mathrm{AS} 44$ & $\begin{array}{l}\mathrm{PE} \\
\text { sire }\end{array}$ & $\begin{array}{l}\checkmark \\
\checkmark\end{array}$ & & & & & & & $\begin{array}{l}\checkmark \\
\checkmark\end{array}$ & $\begin{array}{l}\checkmark \\
\checkmark\end{array}$ & $\checkmark$ \\
\hline L55 & $\begin{array}{l}\mathrm{PE} \\
\text { sire }\end{array}$ & $\checkmark$ & $\checkmark$ & $\checkmark$ & $\checkmark$ & $\checkmark$ & & & & & \\
\hline L15 & $\begin{array}{l}\mathrm{PE} \\
\text { sire }\end{array}$ & $\begin{array}{l}\checkmark \\
\checkmark\end{array}$ & $\checkmark$ & $\checkmark$ & $\checkmark$ & $\checkmark$ & & & & & \\
\hline L25 & $\begin{array}{l}\mathrm{PE} \\
\text { sire }\end{array}$ & $\checkmark$ & $\checkmark$ & $\checkmark$ & $\checkmark$ & $\checkmark$ & & & & & \\
\hline L35 & $\begin{array}{l}\mathrm{PE} \\
\text { sire }\end{array}$ & $\begin{array}{l}\checkmark \\
\checkmark\end{array}$ & $\begin{array}{l}\checkmark \\
\checkmark\end{array}$ & $\begin{array}{l}\checkmark \\
\checkmark\end{array}$ & $\checkmark$ & $\checkmark$ & & & & & \\
\hline L45 & $\begin{array}{l}\mathrm{PE} \\
\text { sire }\end{array}$ & $\checkmark$ & $\checkmark$ & $\begin{array}{l}\checkmark \\
\checkmark\end{array}$ & $\checkmark$ & $\checkmark$ & & & & & \\
\hline L34 & $\begin{array}{l}\mathrm{PE} \\
\text { sire }\end{array}$ & $\begin{array}{l}\checkmark \\
\checkmark\end{array}$ & $\begin{array}{l}\checkmark \\
\checkmark\end{array}$ & $\begin{array}{l}\checkmark \\
\checkmark\end{array}$ & $\checkmark$ & & & & & & \\
\hline
\end{tabular}

vations. Values of $2 \operatorname{lnRL}$ for all models including sire effects were given relative to the base model (REP). Nested models (i.e., one can go from one model to another by zeroing out some parameter(s)) were compared using likelihood-ratio tests. As the likelihood tends to favor complex models with many parameters (Jensen, 2001), the more conservative Bayesian information criterion (BIC) (Schwarz, 1978) and Akaike information criterion (AIC) (Akaike, 1973) were also used, penalizing models with many parameters.

The likelihood-ratio test statistic for two models $i$ and $j$, where $i$ is nested within $j$, is given by:

$$
-2 \ln \Lambda=-2 \ln \frac{\mathrm{L}(i)}{\mathrm{L}(j)} \sim \chi_{\nu_{\mathrm{j}} \nu_{\mathrm{i}}}^{2}
$$

$L(i)$ and $L(j)$ are the restricted likelihoods of the models to be compared, and $\nu_{i}$ and $\nu_{j}$ are the corresponding number of parameters of those models. Related is BIC and AIC, defined as:

$$
\begin{gathered}
\mathrm{BIC}=2 \ln \frac{L(i)}{L(0)}-\left(\nu_{i}-\nu_{0}\right) \times \ln (N-p) \text { and } \\
\mathrm{AIC}=2\left[\ln \frac{L(i)}{L(0)}-\left(\nu_{i}-\nu_{0}\right)\right]
\end{gathered}
$$

where: $N$ is the number of observations, $p$ is the rank of fixed effects incidence matrix, and $\mathrm{L}(0)$ and $\nu_{0}$ are the restricted likelihood and number of parameters of the base model (e.g., REP), respectively. For the likelihood-based criterions, models with the largest values have the best fit.

Models were also compared by their ability to predict randomly excluded observations. These observations were sampled from $\mathrm{PE}$ and herd test-day classes with at least 2 observations each, respectively, and from herd-year classes with at least 4 cows. Random sampling was carried out twice, generating datasets of 14,010 and 13,702 observations, respectively. For both datasets MSEP was calculated as: 


$$
\operatorname{MSEP}=\frac{1}{n} \sum_{i=1}^{n}\left(y_{i}-\hat{y}_{i}\right)^{2}
$$

where: $y_{i}$ is an observation, $\hat{y}_{i}$ is the predicted value of the observation, and $n$ is the total number of observations in the sample. Finally, a weighted mean of MSEP in the 2 datasets was derived. In the calculation, (co)variance components estimated on the basis of the entire dataset were used as the true parameters.

\section{RESULTS AND DISCUSSION}

Results for 2lnRL, BIC, AIC, MSEP, and residual variances from the 2 simple models analyzed with both homogeneous and heterogeneous residual variances (L04 and L05) are presented in Table 3. For the heteroscedastic models, residual variances were largest in beginning of lactation and lowest in late lactation, ranging from 0.28 to 0.50 . Model comparison indicated that although the models assuming heterogenous residual variances were favored on basis of likelihoodbased criteria, there were no differences in predictive ability (MSEP) for models assuming either heterogeneous or homogeneous residual variance. For both variance structures the most complex model (L05) was preferred over the simpler model (L04) based on 2lnRL, BIC, and AIC, while the models ranked approximately equal based on predictive ability. The relative difference in $2 \operatorname{lnRL}$ between L05 and L04 was larger when homogeneous residual variance was assumed. This may be explained by the PE effect "absorbing" some of the heterogeneity of the residual variances, thus favoring more complex modeling of PE effects for likelihood-based criteria. Absorption is also seen from Figure 1, depicting the PE variance and the residual variance by DIM for homogeneous and heterogeneous residual variance. For the models assuming homogeneous residual variance, the slope of the $\mathrm{PE}$ variance trajectory is obviously affected by change in residual variance throughout lactation, demonstrating the ability of the PE effects to absorb heterogeneity of the residuals. Hence, it seems appropriate to model testday SCS with a homogeneous residual variance structure.

Estimated sire variances by DIM for the models REP, L22, L33, W33, L44, LM44, AS44, and L55 are shown in Figure 2. For all these RRM the sire variance was lower in early lactation (0.020 to 0.025$)$ than later (DIM 305; 0.028 to 0.037). This is in agreement with results reported by Haile Mariam et al. (2001) and Mrode and Swanson (2003). Compared with REP, the RRM gave slightly smaller sire variance in the first weeks of lactation, and larger variance later, resulting
Table 3. Estimates of $2 \ln$ restricted likelihoods (2lnRL), Bayesian information criterion (BIC), Akaike information criterion (AIC), mean squared error of predictions (MSEP), and residual variance(s) $\left(\sigma_{e i}^{2}, i\right.$ = lactation period, being 1 for the homoschedastic models, and 1 to 10 for the heteroschedastic models) from 2 models (L04 and L05), with either homogeneous or heterogeneous residual variance structure. The values of $2 \operatorname{lnRL}$ are presented as deviates from values of the L04 model with homogeneous residual variance.

\begin{tabular}{lllllc}
\hline & \multicolumn{2}{c}{ Homogeneous } & & \multicolumn{2}{c}{ Heterogeneous } \\
\cline { 2 - 3 } \cline { 5 - 6 } Model & L04 & L05 & & L04 & L05 \\
\hline $2 \ln R L$ & 0 & 852 & & 708 & 1204 \\
BIC & 0 & 738 & & 645 & 1026 \\
AIC & 0 & 834 & & 698 & 1176 \\
MSEP & 0.7078 & 0.7073 & & 0.7080 & 0.7069 \\
$\sigma_{\text {e1 }}^{2}$ & 0.3915 & 0.3755 & & 0.5008 & 0.4898 \\
$\sigma_{\text {e2 }}^{2}$ & & & & 0.4964 & 0.4544 \\
$\sigma_{\text {e3 }}^{2}$ & & & & 0.4426 & 0.4026 \\
$\sigma_{\text {e4 }}^{2}$ & & & 0.4064 & 0.4087 \\
$\sigma_{\text {e5 }}^{2}$ & & & 0.3794 & 0.3689 \\
$\sigma_{\text {e6 }}^{2}$ & & & 0.3704 & 0.3469 \\
$\sigma_{\text {e7 }}^{2}$ & & & 0.3518 & 0.3481 \\
$\sigma_{\text {e8 }}^{2}$ & & & 0.3429 & 0.3424 \\
$\sigma_{\text {e9 }}^{2}$ & & & 0.3449 & 0.3250 \\
$\sigma_{\text {e10 }}^{2}$ & & & 0.2787 & 0.3096 \\
\hline
\end{tabular}

${ }^{1}$ Weighted mean of MSEP from two independent samples of 14,010 and 13,702 observations, respectively.

in a larger average genetic variance for $R R M$ than for REP.

Estimated PE variances by DIM for the models REP, L22, W33, L33, L44, LM44, AS44, and L55 are shown in Figure 3. With the exception of L22, the PE variances were highest in the beginning of the lactation (0.92 to 1.17), and with a wavy pattern for the first 2 mo. After 2 mo, the RRM with at least 4 polynomials for both sire and PE effects showed more stable PE variances (0.78 to 0.86 at DIM 305), whereas models with lower order of fit showed a wavier pattern. The $\mathrm{PE}$ variance was consistently higher for RRM than for REP. This increase, as well as the increase for sire variance (above), is probably due to improved model flexibility, allowing separation of effects that would otherwise be captured by the error term. As sire models were fitted, the PE effect is expected to contain three quarters of the additive genetic variance. This may affect the trajectory of the PE variance by DIM, but is not expected to affect the trajectory of heritability. Mrode and Swanson (2001) reported that the PE variance curve by DIM for SCS had similar shape for animal and sire models, but, as expected, that the PE variance was slightly higher for the sire model.

Heritabilities of daily SCS for the models REP, L22, W33, L33, L44, LM44, AS44, and L55 are shown in Figure 4. Heritability increased with stage of lactation from 0.05 to 0.07 for DIM 6 to 0.08 to 0.12 for DIM 


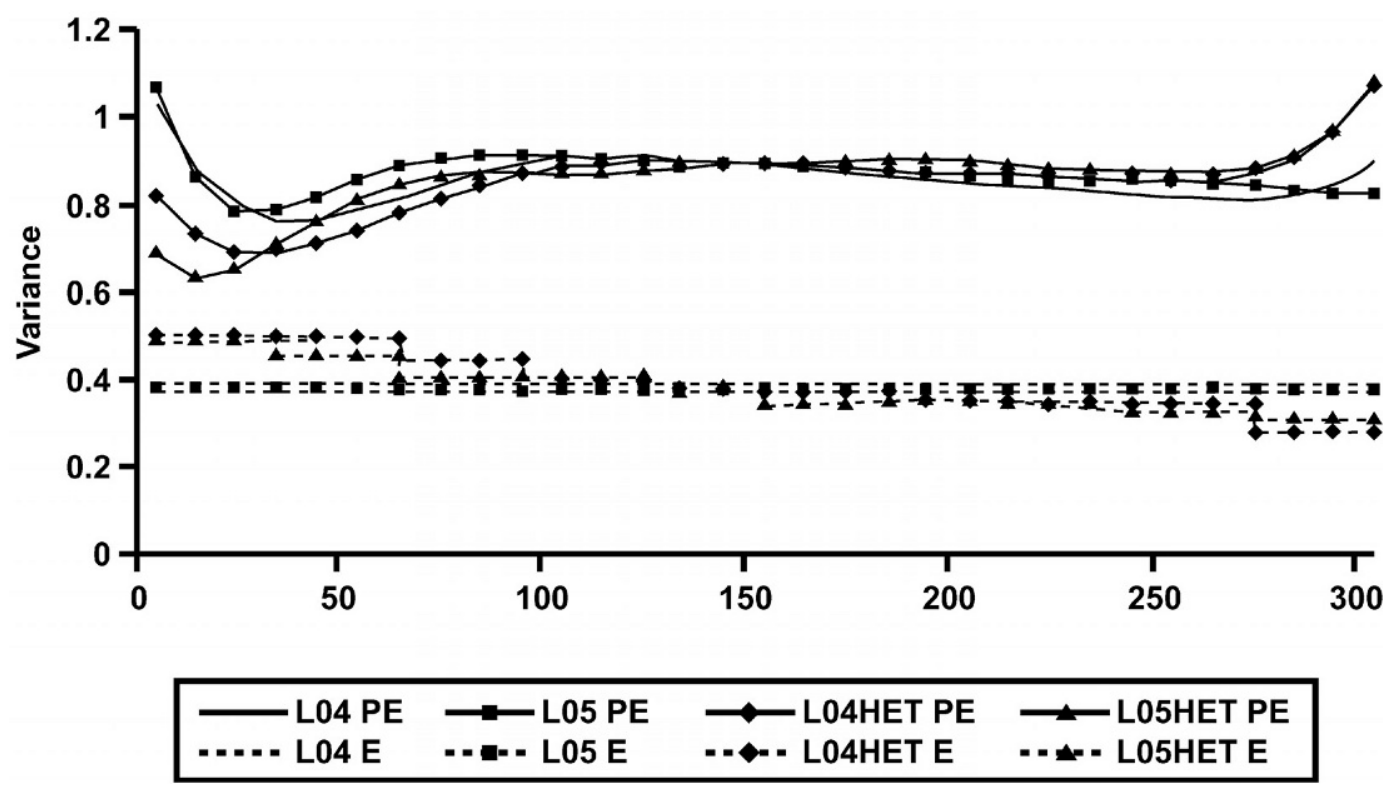

Figure 1. Trajectory of permanent environmental (PE) and residual (E) variances of SCS by DIM from two random regression test-day models with up to third (L04) and fourth (L05) order Legendre polynomials for permanent environmental effect, respectively. Residual variance was assumed either homogeneous or heterogeneous (HET).

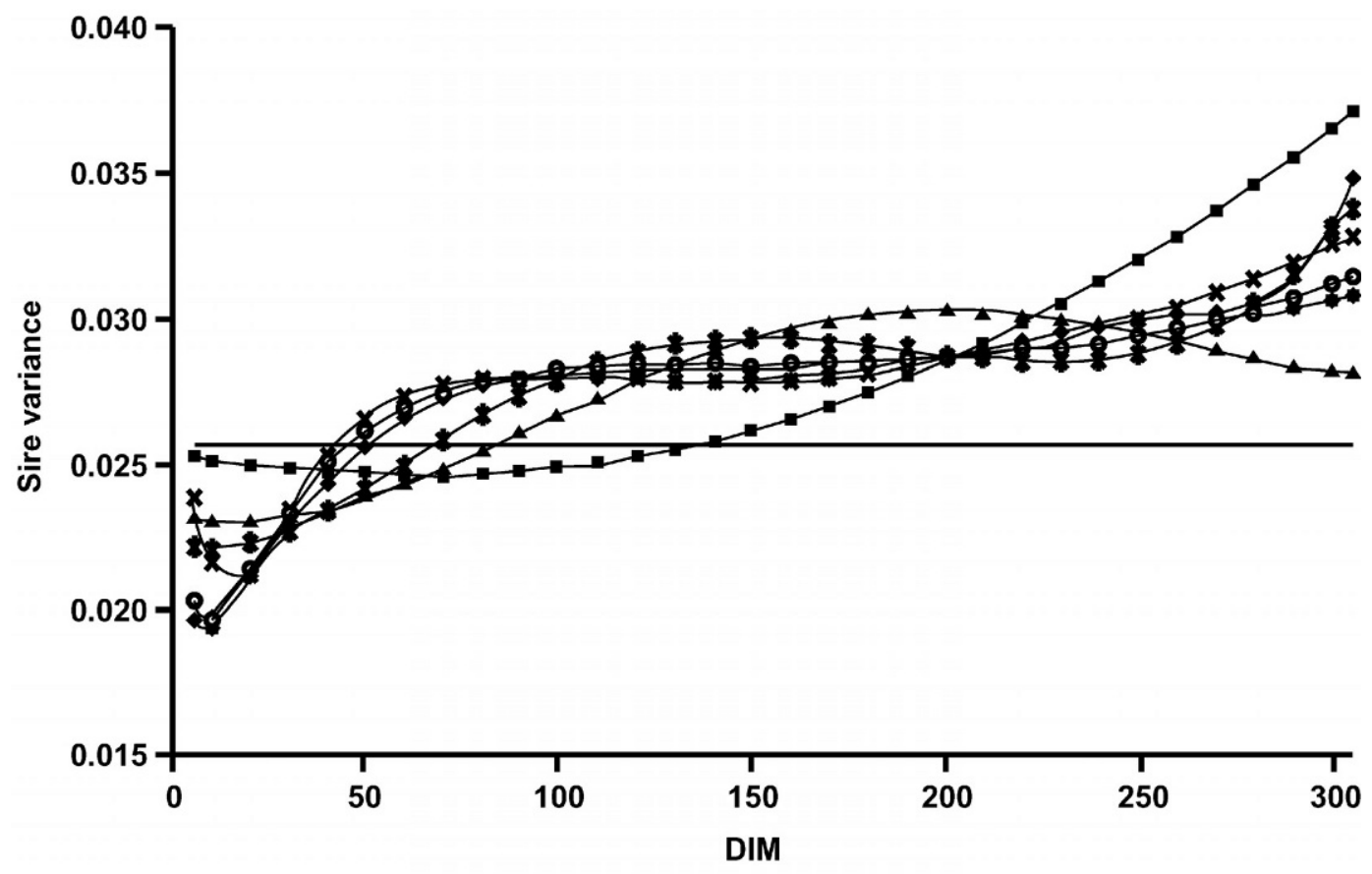

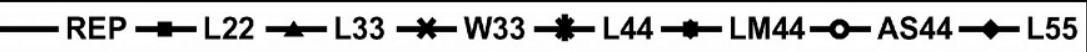

Figure 2. Trajectory of estimated sire variance of SCS by DIM, from a repeatablity test-day model (REP) and 7 test-day models with different random regression functions: first- to fourth-order Legendre polynomials (L22, L33, L44, L55), Modified Wilmink curve (W33), Lidauer-Mäntysaari curve (LM44), and modified Ali-Schaeffer curve (AS44). 

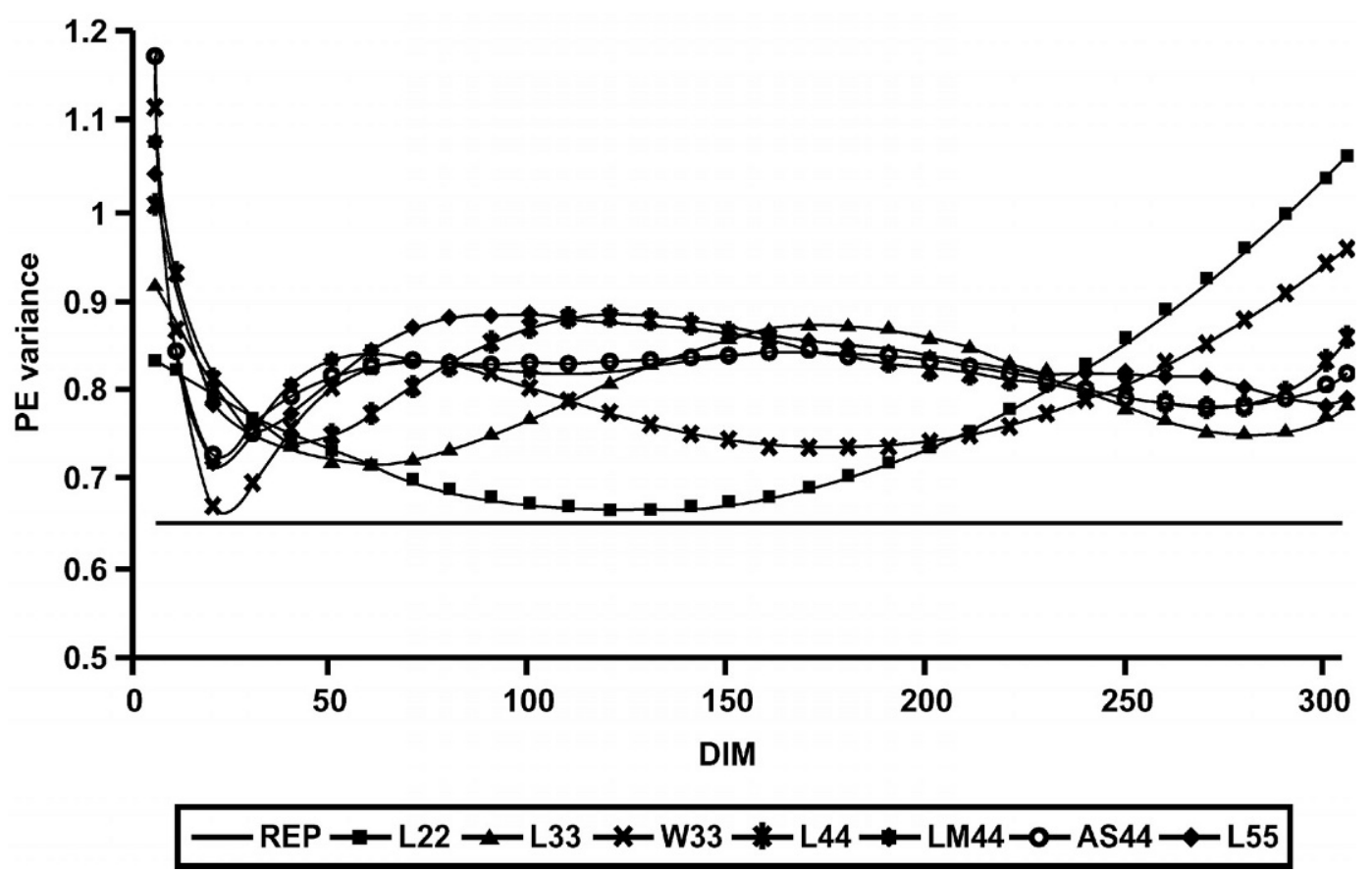

Figure 3. Trajectory of estimated permanent environmental (PE) variance of SCS by DIM, from a repeatablity test-day model (REP) and 7 test-day models with different random regression functions: first- to fourth-order Legendre polynomials (L22, L33, L44, L55), Modified Wilmink curve (W33), Lidauer-Mäntysaari curve (LM44), and modified Ali-Shaeffer curve (AS44).

305. This is in agreement with heritabilities for SCS reported by Haile Mariam et al. (2001) and Mrode and Swanson (2003).

The genetic correlations between SCS at different DIM for each of the RRM with the same RR function for both sire and PE effects are shown in Figure 5. As expected, for all models the highest correlations were found for consecutive DIM, while the lowest were between SCS at DIM early and late in lactation. Random regression models with Legendre polynomials showed consistently higher genetic correlations for the most distant DIM compared to the other models. For L22, L33, L44, and L55 the genetic correlations between DIM 6 and DIM 305 were 0.71, 0.67, 0.58, and 0.57, respectively, whereas W33, LM44, and AS44 showed lower genetic correlations $(0.38,0.50$, and 0.46 , respectively). Haile-Mariam et al. (2001) reported smaller genetic correlation (0.33) between SCS at the most distant DIM, using RR of second order for the sire effect.

Figure 6 shows sire variance by DIM for the models REP, L15, L22, L25, L33, L35, L44, and L45. Sire variance trajectories for models L15 and L25 were systematically lower than the corresponding trajectories for the models REP and L22, respectively. However, sire variance trajectories were similar in the models L35 and L45 relative to L33 and L44, respectively.
Hence, lower order of fit for the sire effect compared with the PE effect probably results in underestimation of the genetic variance, most pronounced when sire effect is fitted only using an intercept (zeroth order) or linear regression (first order).

Model comparison based on the values of $2 \operatorname{lnRL}$, BIC, AIC, residual variance, and MSEP for the former 12 models and for L34 are presented in Table 4. Generally, the residual variances decreased and $2 \operatorname{lnRL}$ increased as the number of parameters in the model increased. Based on likelihood-ratio tests, BIC, and AIC, all RRM were improvements relative to REP. In addition, introducing $R R$ coefficients to the models reduced residual variance and MSEP. The models with $3 \mathrm{RR}$ coefficients for $\mathrm{PE}$ and sire effects were ranked over L22 for all criteria. Within these models, L33 had the smallest residual variance and MSEP, and ranked highest based on the likelihood-based criteria (2lnRL, BIC, and AIC). L33 was therefore preferred over the W33 model.

Increasing the number of RR coefficients from 3 to 4 (L33 to LM44 or L44) resulted in a highly significant increase of likelihood, and all model selection criteria ranked the models with 4 RR coefficients (L44, LM44, and AS44) over the models with lower fit. Among models with $4 \mathrm{RR}$ coefficients, L44 had the smallest residual variance and MSEP, whereas LM44 was ranked 


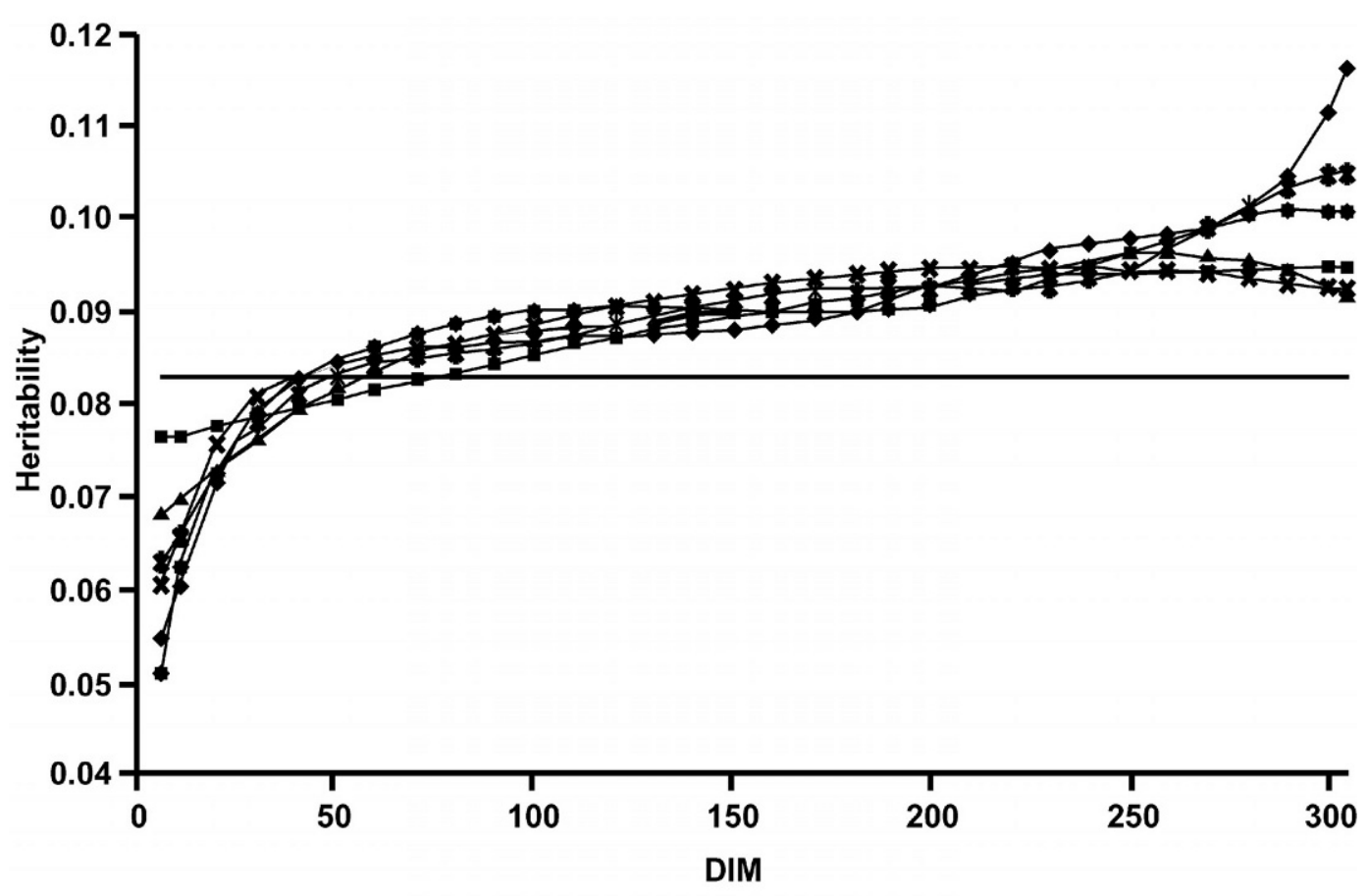

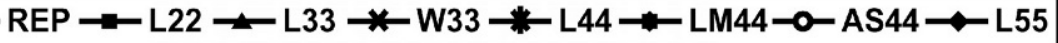

Figure 4. Trajectory of estimated heritability of SCS by DIM, from a repeatablity test-day model (REP) and 7 test-day models with different random regression functions: first- to fourth-order Legendre polynomials (L22, L33, L44, L55), Modified Wilmink curve (W33), Lidauer-Mäntysaari curve (LM44), and modified Ali-Shaeffer curve (AS44).

highest based on 2lnRL, AIC, and BIC. Model comparison within these models was not conclusive, but there seem to be small differences between the models. Legendre polynomials were preferred over other polynomials due to faster convergence in estimation of dispersion parameters.

Increasing the number of RR coefficients from 4 to 5 (from L44 to L55) resulted in reduced residual variance, a highly significant increase of the likelihood, as well as increased BIC and AIC. However, based on residual variance and MSEP, L55 and the models with $5 \mathrm{RR}$ coefficients for PE effect and reduced order of fit for sire effect (L15, L25, L35, and L45) were ranked approximately equal. The latter models, except L15, ranked over L55 based on BIC, with L25 ranking highest of all models. However, as previously mentioned, the L25 model probably underestimates sire variance. Hence, sire effects should be modeled with at least second order of fit in models with higher order of fit for PE effects.

Based on MSEP, the models with 5 RR coefficients for PE (e.g., L55) were ranked approximately equal to some of the models with 4 RR coefficients (e.g., L44), indicating that higher order of fit did not substantially improve predictive ability, which could be explained by the low number of records per cow (Table 1). However, by predicting randomly excluded observations, number of observations per cow used for prediction was slightly reduced (4.19 vs. 4.43 ), which may have an effect on the relative difference in predictive ability. Contrary, the likelihood-based criteria indicated that the models with the most complex modeling of $\mathrm{PE}$ effects should be preferred. This is in accordance with the results from the comparison of heteroscedastic and homoscedastic models, indicating that, based on likelihood, more complex modeling of PE effects was preferred for models assuming homogeneous residual variance, while predictive abilities of the models were not affected by this assumption. Hence, as some of the models with 4 and 5 polynomials used to fit the $\mathrm{PE}$ effect showed approximately the same predictive ability, the simpler models were preferred.

The model comparisons lead forward to a model with second-order Legendre polynomials for sire effects and third-order Legendre polynomials for PE effects (L34), which are most easily tested against the L44 model (Table 4). A likelihood ratio test indicated a moderate significant $(P<0.1)$ reduction in likelihood going from L44 to L34. AIC, residual variance and MSEP for the 2 models were similar, while BIC ranked L34 over 
L22

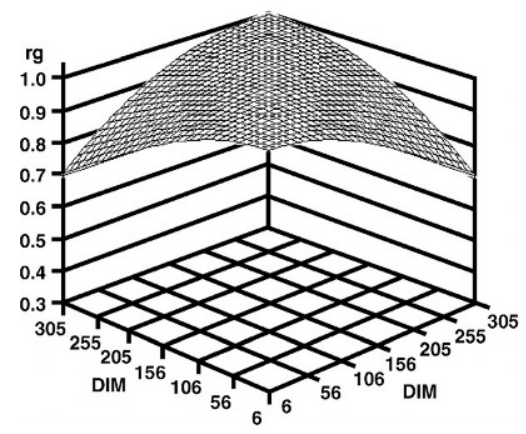

L44

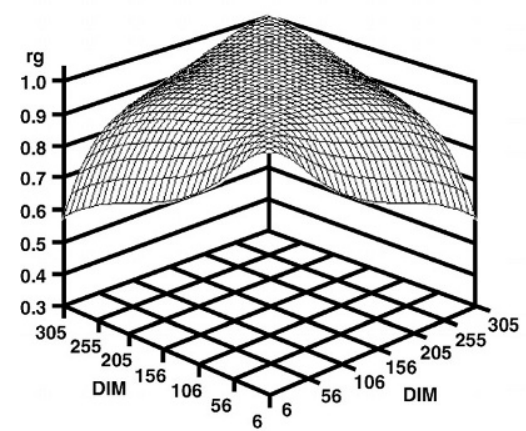

L55

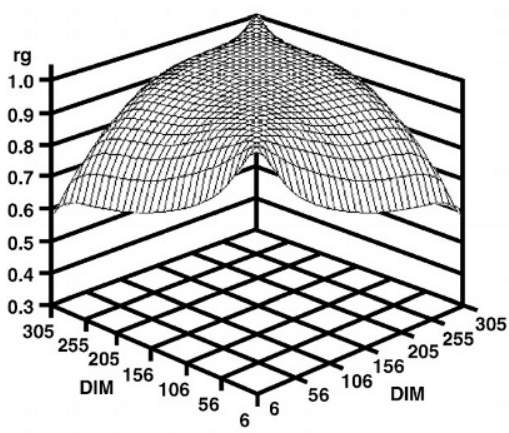

L33

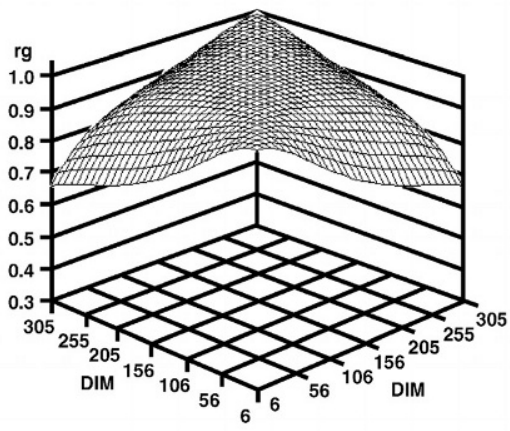

LM44

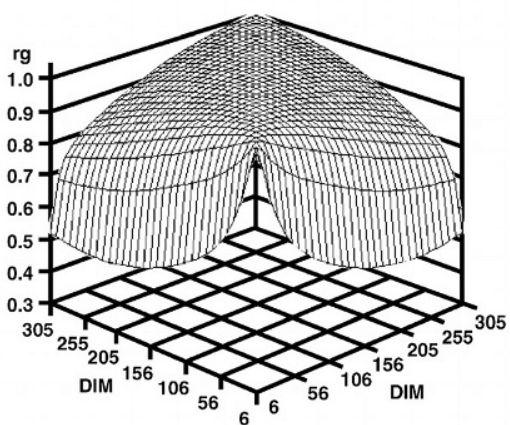

W33

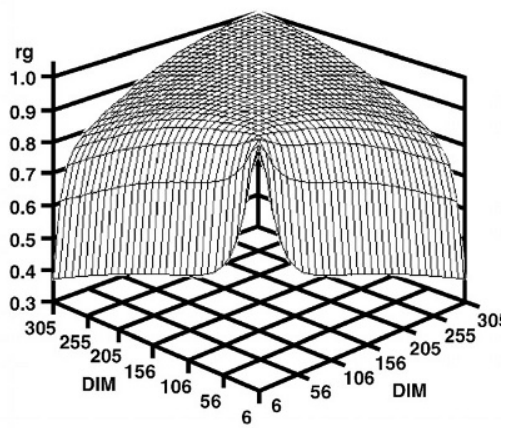

AS44

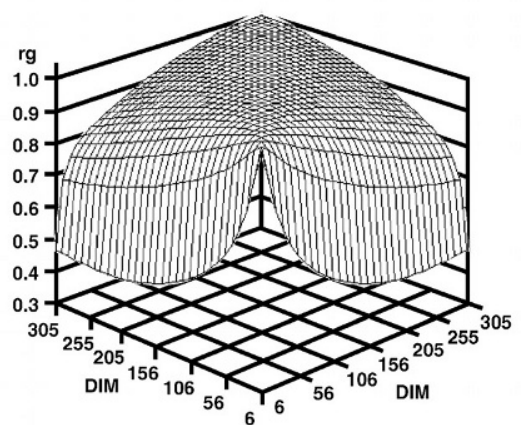

Figure 5. Estimated genetic correlations $\left(r_{g}\right)$ between SCS at different DIM, estimated with the random regression models: L22, L33, W33, L44, LM44, AS44, and L55.

L44. Therefore, since L34 has fewer parameters, it should have preference over L44. Trajectories of sire and PE variances by DIM for L34 (Figure 7) were close to the trajectories presented for the models L35 (Figure 6) and L44 (Figure 3), respectively. The heritability of SCS based on L34 was 0.07 in the beginning of lactation, and 0.09 to 0.10 towards the end of the lactation.
In Figure 7, the trajectories of sire, $\mathrm{PE}$, and residual variances by DIM are presented for the L34 model fitted with either homogeneous or heterogeneous residual variance structure. For the PE effect, the same pattern was seen as that in Figure 1, demonstrating absorption of heterogeneity of the residual variance into the PE effect, when residual variance was assumed homogeneous. Sire variance trajectories (Fig- 


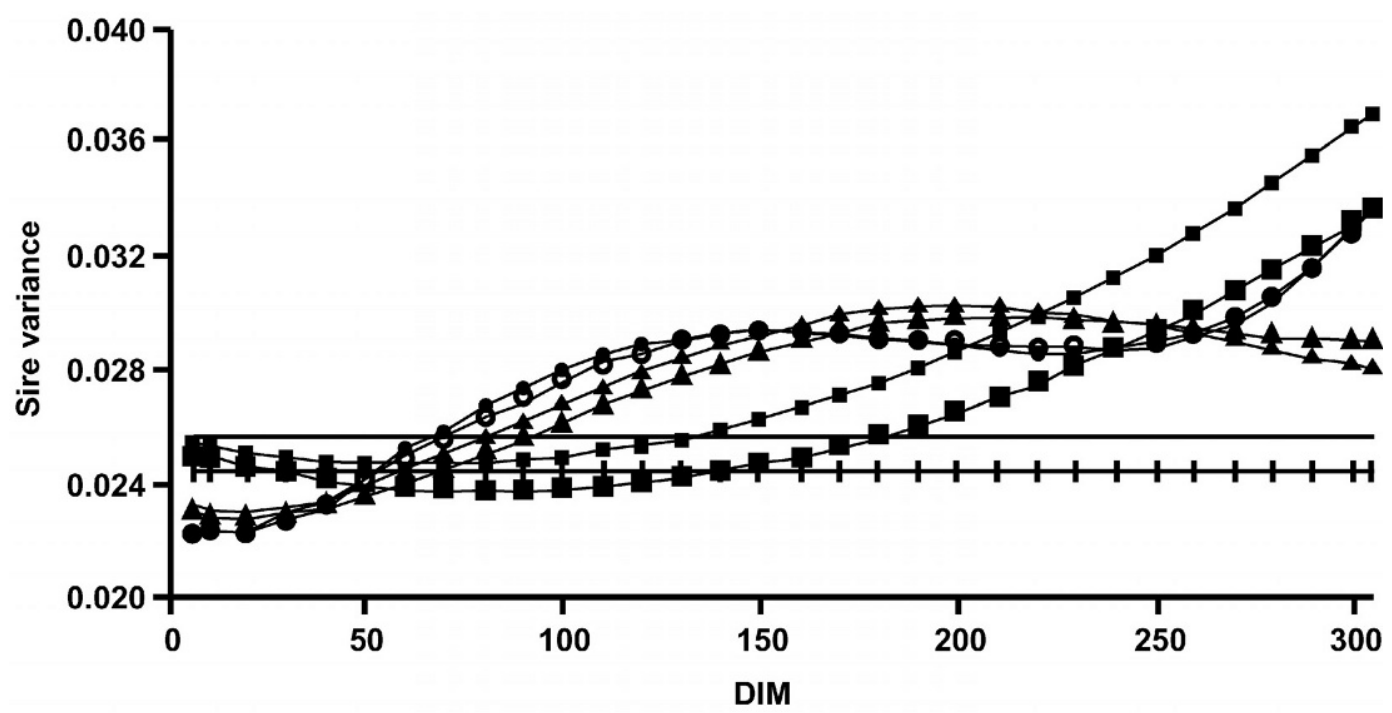

$\mathrm{REP}+\mathrm{L} 15 \rightarrow-\mathrm{L} 22 \rightarrow-\mathrm{L} 25 \rightarrow \mathrm{L} 33 \rightarrow \mathrm{L} 35 \rightarrow \mathrm{L} 44 \rightarrow \mathrm{L} 45$

Figure 6. Trajectory of the estimated variance of sire effects by DIM, from a reperatablity test-day model (REP) and 7 test-day models, using first- to fourth-order Legendre polynomials for sire and PE effects (L15, L22, L25, L33, L35, L44, and L45).

ure 7) were identical for both residual variance structures, leading forward to rather similar trajectories of heritability by DIM (Figure 8). Consequently, it is unlikely that assumptions of homogeneous/heterogeneous residual variance will affect the genetic evaluation of sires.

Models with more than 6 RR coefficients for sire or PE effects were not used due to computing limitations. However, since L44 and L55 ranked approximately equal based on MSEP, a further extension on the order of the polynomials in the model would probably not improve predictive ability in a substantial manner.

\section{CONCLUSIONS}

Random regression models using Legendre polynomials seem well suited for genetic analysis of SCS compared with other random regression functions. For

Table 4. Estimates of $2 \mathrm{ln}$ restricted likelihoods (2lnRL), Bayesian information criterion (BIC), Akaike information criterion (AIC), residual variance $\left(\sigma_{\mathrm{e}}^{2}\right)$, and mean squared error of predictions (MSEP) from a repeatability test-day model (REP) and 12 random regression test-day models (W33, L33, L44, L55, LM44, AS44, L15, L25, L35, L45, and L34). The values of 2lnRL are presented as deviates from values of the REP model.

\begin{tabular}{lrrrrr}
\hline Model & 2lnRL & \multicolumn{1}{c}{ BIC } & \multicolumn{1}{c}{ AIC } & \multicolumn{1}{l}{$\sigma_{\mathrm{e}}^{2}$} & MSEP $^{1}$ \\
\hline REP & 0 & 0 & 0 & 0.5628 & 0.7614 \\
L22 & 9730 & 9654 & 9718 & 0.4703 & 0.7270 \\
L33 & 15,356 & 15,203 & 15,332 & 0.4198 & 0.7109 \\
W33 & 14,804 & 14,652 & 14,780 & 0.4326 & 0.7146 \\
L44 & 17,338 & 17,084 & 17,298 & 0.3916 & 0.7062 \\
LM44 & 17,410 & 17,156 & 17,370 & 0.3980 & 0.7073 \\
AS44 & 17,390 & 17,136 & 17,350 & 0.3990 & 0.7070 \\
L55 & 18,064 & 17,684 & 18,004 & 0.3756 & 0.7056 \\
L15 & 17,861 & 17,658 & 17,829 & 0.3755 & 0.7066 \\
L25 & 18,001 & 17,773 & 17,965 & 0.3755 & 0.7061 \\
L35 & 18,037 & 17,771 & 17,995 & 0.3756 & 0.7059 \\
L45 & 18,044 & 17,727 & 17,994 & 0.3756 & 0.7057 \\
L34 & 17,329 & 17,126 & 17,297 & 0.3916 & 0.7064 \\
L34HET & 18,182 & 17,865 & 18,132 & - & 0.7059 \\
\hline
\end{tabular}

${ }^{1}$ Weighted mean of MSEP from two independent samples of 14,010 and 13,702 observations, respectively.

${ }^{2}$ The L34 model assuming heterogeneous residual variance. 


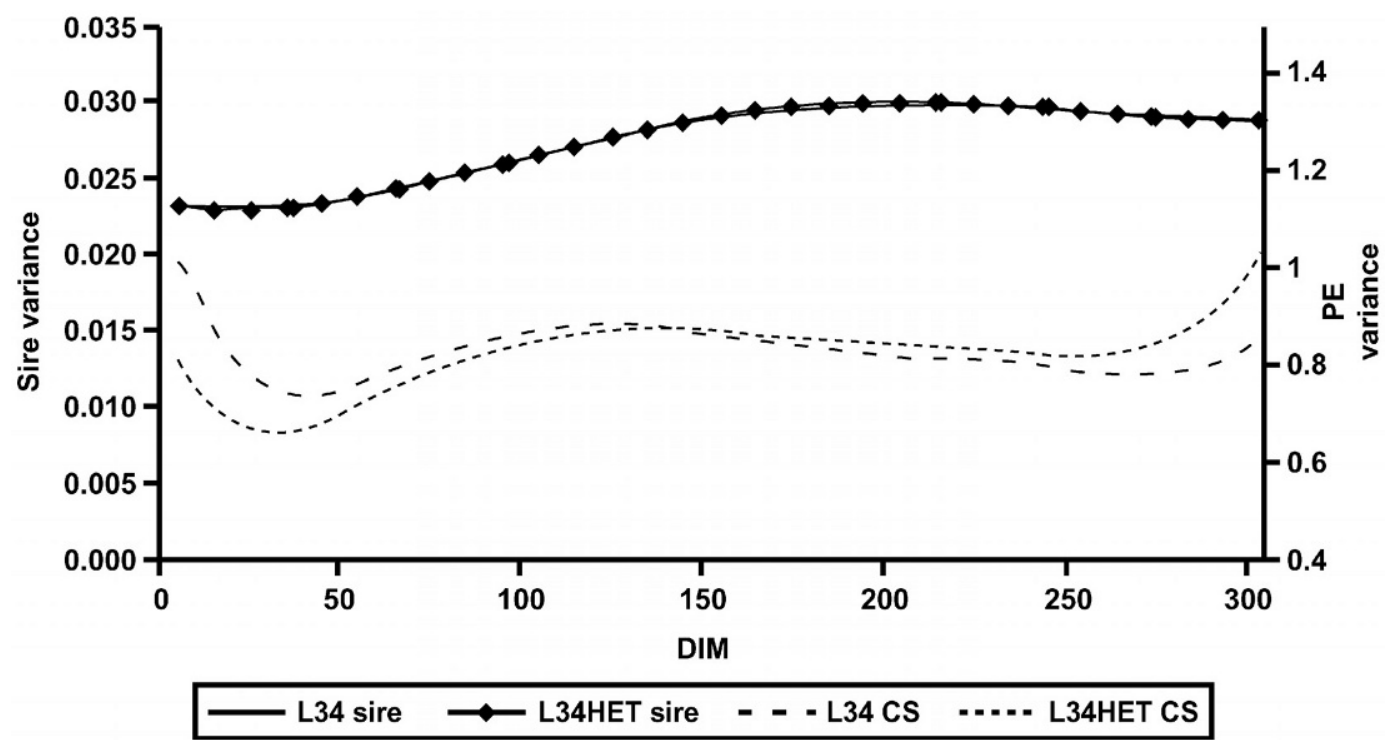

Figure 7. Trajectory of estimated sire and permanent environmental (PE) variances of SCS by DIM, from a random regression test-day model with up to second- and third-order Legendre polynomials for sire and PE effects, respectively. Residual variance was assumed either homogeneous (L34) or heterogeneous (L34HET).

models with homogeneous residual variance, the $\mathrm{PE}$ effect absorbs heterogeneity of residual variance, while predictive ability was not affected by residual variance structure. Given complex modeling of $\mathrm{PE}$ effects, use of homoschedastic random regression models for test-day SCS seems appropriate. It was shown that models with lower order of fit for sire effects than for $\mathrm{PE}$ effects had preference, but may underestimate sire variance components, particularly when sire effects are modeled only using an intercept or first-order ran-

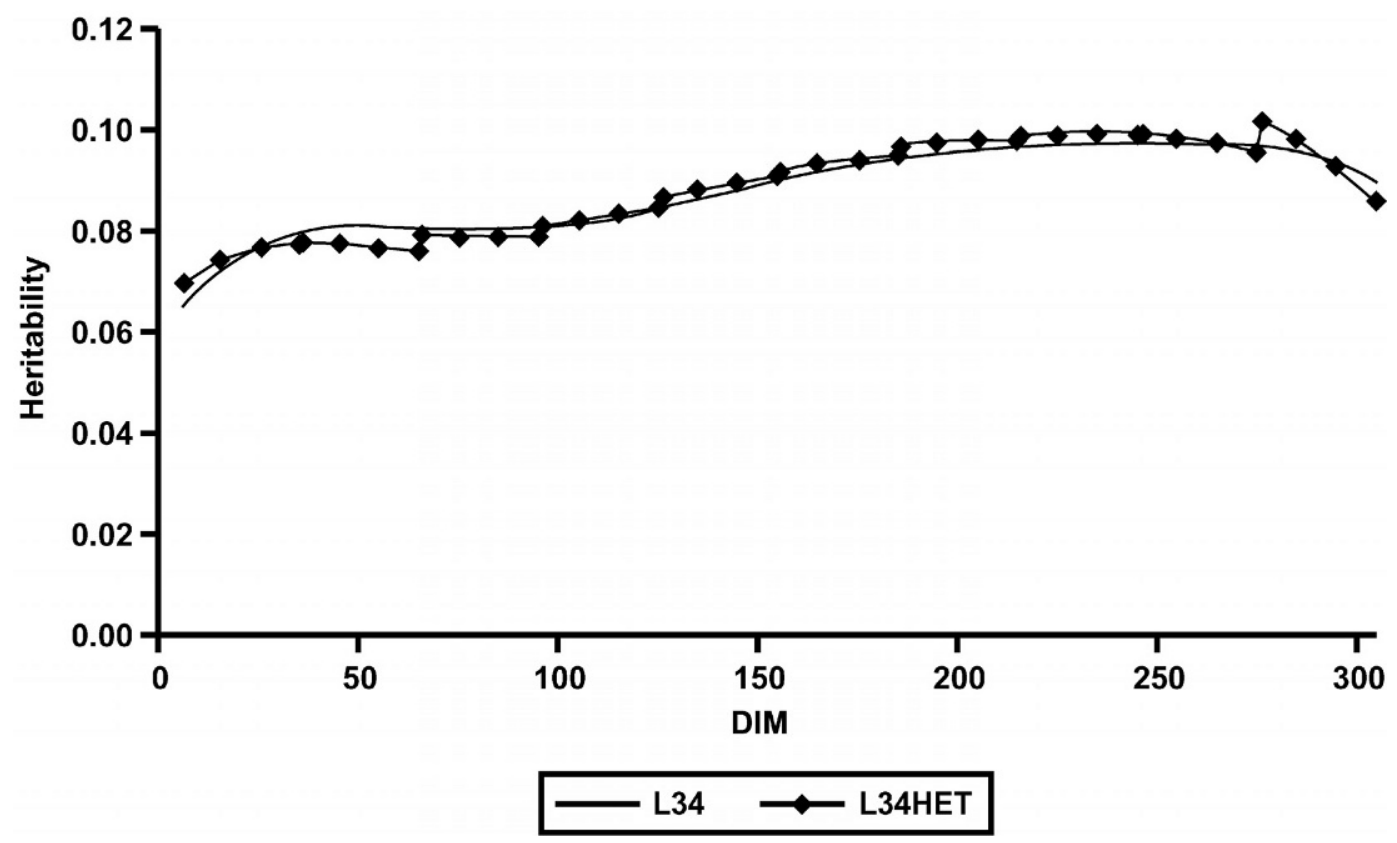

Figure 8. Trajectory of estimated heritability of SCS by DIM, from a random regression test-day model with up to second- and thirdorder Legendre polynomials for sire and PE effects, respectively. Residual variance was assumed either homogeneous (L34) or heterogeneous (L34HET). 
dom regression. Hence, second order of fit was preferred for sire effects. For PE effects, the most highly parameterized model did not substantially improve predictive ability. Hence, a model with third order of fit for PE effects was preferred. The choice of model for these data required careful inspection of both estimated variance components and various model selection criteria; likelihood-ratio test statistic, likelihoodbased criterions penalizing models with many parameters, residual variance, and mean square error of prediction. For the chosen model with second- and thirdorder Legendre polynomials for sire and PE effects, respectively, the heritability of SCS increased with DIM, from 0.07 in the beginning to 0.09 to 0.10 in late lactation. Genetic correlations between SCS at different stages of lactation were high, even for the most distant DIM. Trajectories of sire variance and heritability were similar assuming either homogeneous or heterogeneous residual variances.

\section{ACKNOWLEDGMENTS}

Access to the data was given by the Norwegian Dairy Herd Recording System (Husdyrkontrollen) in agreement no. 6/1998. GENO Breeding and A.I. Association is acknowledged for providing pedigree information for bulls. The project has received funding from the Research Council of Norway, TINE Norwegian Dairies BA, GENO Breeding and A.I. Association, and The Nordic Academy for Advanced Study (NorFA).

\section{REFERENCES}

Akaike, H. 1973. Information theory as an extension of the maximum likelihood principle. Pages 267-281 in 2nd Int. Symp. Info. Theory. B. N. Petrov and F. Csaki, ed. Akademiai Kiado, Budapest, Hungary.

Ali, T. E., and L. R. Schaeffer. 1987. Accounting for covariances among test-day milk yields in dairy cows. Can. J. Anim. Sci. 67:637-644.

Gilmour, A. R., B. R. Bullis, S. J. Welham, and R. Thompson. 1999. ASREML Reference Manual. NSW Agric. Biometric Bulletin. No. 3. Orange Agricultural Institute, Orange, Australia.

Haile Mariam, M., M. E. Goddard, and P. J. Bowman. 2001. Estimates of genetic parameters for daily somatic cell count of Australian dairy cattle. J. Dairy Sci. 84:1255-1264.

Heringstad, B., G. Klemetsdal, and J. Ruane. 1999. Clinical mastitis in Norwegian Cattle: Frequency, variance components, and genetic correlation with protein yield. J. Dairy Sci. 82:1325-1330.

Heringstad, B., G. Klemetsdal, and J. Ruane. 2000. Selection for mastitis resistance in dairy cattle-a review with focus on the situation in the Nordic countries. Livest. Prod. Sci. 64:95-106.
Heringstad, B., R. Rekaya, D. Gianola, G. Klemetsdal, and K. A. Weigel. 2003. Genetic change for clinical mastitis in Norwegian Cattle: A threshold model analysis. J. Dairy Sci. 86:369-375.

International Bull Evaluation Service. 1996. Sire Eveluation procedures for non-dairy-production and growth \& beef production traits practised in various countries 1996. INTERBULL Bulletin No. 13. Int. Bull Eval. Serv., Uppsala, Sweden.

Jensen, J. 2001. Genetic evaluation of dairy cattle using test-day models. J. Dairy Sci. 84:2803-2812.

Kettunen, A., E. A. Mäntysaari, and J. Pösö. 2000. Estimation of genetic parameters for daily milk yield of primiparous Ayrshire cows by random regression test-day models. Livest. Prod. Sci. 66:251-261.

Lidauer, M., and E. A. Mäntysaari. 1999. Multiple trait reduced rank random regression test-day model for production traits. Pages 74-80 in INTERBULL Bulletin No. 22. Int. Bull Eval. Serv., Uppsala, Sweden.

Madsen, P., and J. Jensen. 2000. Version 6, release 4. A user's guide to DMU. A package for analysing multivariate mixed models.

Madsen, P., S. M. Nielsen, M. D. Rasmussen, N. O. Klastrup, N. E. Jensen, P. T. Jensen, P. S. Madsen, B. Larsen, and J. HyldgaardJensen. 1987. Investigations on genetic resistance to Bovine mastitis. Report no. 621 from the National Institute of Animal Science, Denmark.

Mrode, R. A., and G. J. T. Swanson. 1996. Genetic and statistical properties of somatic cell count and its suitability as an indirect means of reducing the incidence of mastitis in dairy cattle. Anim. Breed. Abstr. 64:847-857.

Mrode, R. A., and G. J. T. Swanson. 2001. Genetic parameters for test-day somatic cell counts for the first three lactations using a random regression model. Pages 193-196 in INTERBULL Bulletin No. 27. Int. Bull Eval. Serv., Uppsala, Sweden.

Mrode, R. A., and G. J. T. Swanson. 2003. Estimation of genetic parameters for somatic cell count in the first three lactations using random regression. Livest. Prod. Sci. 79:239-247.

Mrode, R. A., G. J. T. Swanson, and M. S. Winters. 1998. Genetic parameters and evaluations for somatic cell counts and its relationship with production and type traits in some dairy breeds in the United Kingdom. Anim. Sci. 66:569-576.

Ødegård, J., G. Klemetsdal, and B. Heringstad. 2003. Genetic improvement of mastitis resistance: Validation of somatic cell score and clinical mastitis as selection criteria. J. Dairy Sci. 86:4129-4136.

Pool, M. H., and T. H. E. Meuwissen. 1999. Prediction of daily milk yields from a limited number of test-days using test-day models. J. Dairy Sci. 82:1555-1564.

Reents, R., J. C. M. Dekkers, and L. R. Schaeffer. 1994. Genetic parameters of test-day somatic cell counts and production traits. Proc. 5th World Congr. Appl. Livest. Prod., Guelph, Canada 17:120-123.

Schukken, Y. H., K. E. Leslie, A. J. Weersink, S. W. Martin. 1992. Ontario bulk milk somatic cell count program. II. Population dynamics of bulk milk somatic cell counts. J. Dairy Sci. 75:3359-3366.

Schwarz, G. 1978. Estimating the dimension of a model. Ann. Stat. 6:461-464.

Van der Werf, J. H. J., M. E. Goddard, and K. Meyer. 1998. The use of covariance functions and random regressions for genetic evaluation of milk production based on test-day records. J. Dairy Sci. 81:3300-3308.

Wilmink, J. B. M. 1987. Adjustment of test-day milk, fat and protein yield for age, season and stage of lactation. Livest. Prod. Sci. 16:335-348. 